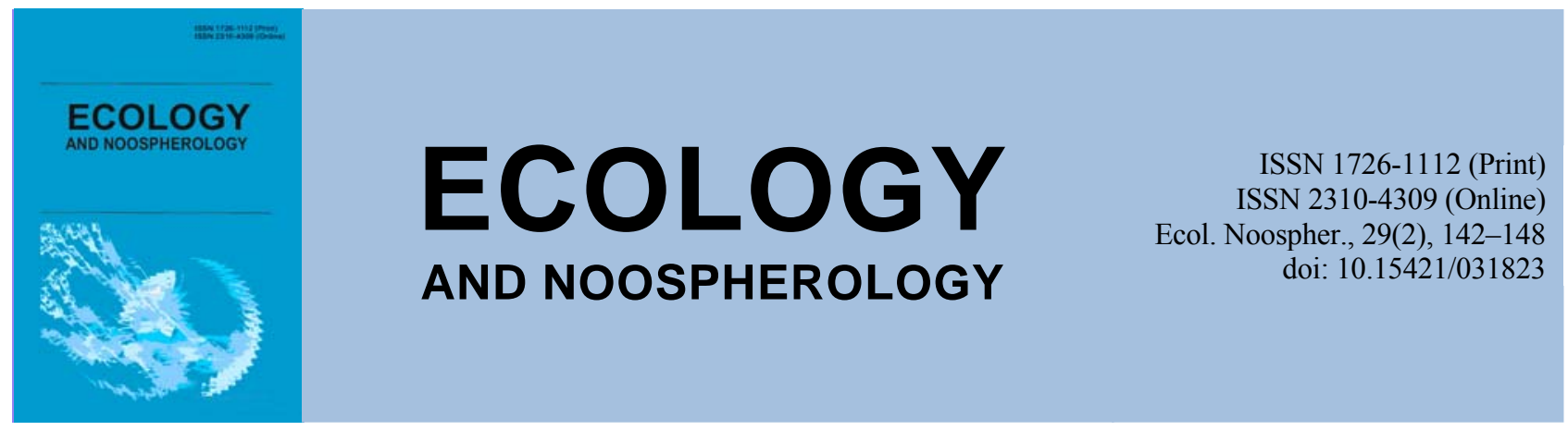

\title{
Modern condition and analysis of anthropogenous-climatic transformation of vegetation of lakes of the Northern Steppe Land
}

\author{
N. O. Roshchyna \\ Oles Honchar Dnipro National University, Dnipro, Ukraine
}

Article info

Received 22.09.2018

Received in revised form

29.09.2018

Accepted 01.10.2018

Oles Honchar Dnipro

National University,

Gagarin Ave., 72, Dnipro,

49010, Ukraine.

Tel.: +38-097-774-43-27

E-mail:botanik_N@ua.fm
Roshchyna, N. O. (2018). Modern condition and analysis of anthropogenous-climatic transformation of vegetation of lakes of the northern Steppe land. Ecology and Noospherology, 29(2), 142-148. doi:10.15421/031823

In this article, the current and former distribution of higher aquatic vegetation has been analyzed for floodplain lakes, arenas lakes and third terraces lakes in the valleys of large and medium North-Steppe Dnieper rivers. The article is devoted to the current state analysis of the higher aquatic vegetation at North-Steppe Dnieper lakes, its dynamics over a long-term period, as well as the determination of the nature and extent of anthropogenic-climatic changes in vegetation. Anthropogenic influence is a major threat to the development and functioning of most aquatic ecosystems. Since the twentieth century, it has been intensified by trends to long-term climate changes, which are also largely result of human activity. Increasing temperature of the winter season does not contribute to snow accumulation. Reduction of snow accumulation (frequent thaws during the winter), regulation of river flow (formation of a reservoirs cascade and ponds) and accumulation of melt water in artificial reservoirs led to the smoothing of the peak of the spring flood. Thus, the factor that provided spring washing of floodplain lakes, limited their overgrowing by air-water vegetation and their waterlogging disappeared. The anthropogenic factors that influence negatively include: intensification of agriculture, plowing of coastal areas, unreasonable land reclamation, overgrazing, development of transport and engineering infrastructure, urbanization, recreation, and chemical pollution. The presented data was obtained on the basis of processing our own research materials of 2009-2018 and literary and archival materials analysis (the herbarium of the Dnipropetrovs'k National University and the archive of the Research Institute of Biology). Natural Northern Steppe Dnieper lakes are located mainly in river valleys, so the study area was conventionally divided into sections: the large river valley (Dnieper) and the middle rivers valleys (Samara and Orel). Three ecological groups of macrophytes were reviewed and compared: hydatofites (submerged species), pleistophytes (species with floating leaves) and helophytes (air-water species). The vegetation of Dnieper floodplain lakes practically did not change for all three formation groups. The number of immersed plants communities within the floodplains of medium-sized rivers has decreased by three. The pleistophytes and helophytes associations decreased to fragments of associations. The lakes vegetation within the sandy Dnieper terrace practically did not change for all three formation groups. The submerged lakes plants associations within the sandy medium-sized rivers terraces have been reduced by two. As part of the lakes vegetation on the Dnipro saline terraces, fragments of associations of the two species are considered extinct. A new association of southern adventive species Ruppia maritima L. has appeared within the limits of the middle rivers saline terrace. Changes in higher aquatic vegetation are characteristic of all types of lakes. Changes occur in the direction of crowding out higher aquatic vegetation communities by airborne plant communities. The consequence of the anthropogenic-climatic transformation of aquatic ecosystems is increased mineralization, siltation, and, as a result, intensive overgrowing of lakes by aboriginal and adventive species with a wide ecological amplitude (replacement of sensitive to environmental changes species).

Keywords: higher aquatic vegetation; anthropogenic and climatic changes; formations; associations; submerged vegetation; vegetation with floating leaves; air-aquatic vegetation 


\title{
Сучасний стан та антропогенно-кліматична трансформація рослинності озер Північно-Степового Придніпров'я
}

\author{
Н. О. Рощина
}

\section{Дніпровський національний університет імені Олеся Гончара, Дніпро, Україна}

\begin{abstract}
Дана стаття присвячена аналізу сучасного стану вищої водної рослинності озер Північно-Степового Придніпров'я, ії динаміки за багаторічний період, а також визначенню характеру та ступеня іï антропогенно-кліматичних змін. Представлені дані отримані на основі обробки матеріалів власних досліджень у 2009-2018 рр. та аналізу літературних та архівних матеріалів (гербарію ДНУ та архіву НДІ біології). Природні озера Північно-Степового Придніпров'я розташовані в основному в долинах річок, тому територію умовно було поділено на ділянки: долину великої ріки (Дніпро) та долини середніх річок (Самара та Оріль). Надано порівняльні дані 3 екологічних груп макрофітів: гідатофітів, плейстофітів, гелофітів. Зміни вищої водної рослинності характерні для озер усіх типів. Вони проходять в цілому у напрямку зміни угруповань вищої водної рослинності угрупованнями повітряно-водних рослин. Результатом антропогенно-кліматичної трансформації водних екосистем є підвищення мінералізації, замулення i, як наслідок, інтенсивне заростання озер аборигенними та адвентивними видами 3 широкою екологічною амплітудою (заміщення ними видів, чутливих до змін середовища).
\end{abstract}

Ключові слова: вища водна рослинність; антропогенно-кліматичні зміни; формації; асоціації; занурена рослинність; рослинність 3 плаваючим листям; повітряно-водна рослинність

\section{Ветуп}

У проблемі раціонального природокористування особливе місце займає збереження водних ресурсів, у конкретному випадку озерних екосистем. Це питання $\epsilon$ особливо актуальним через посушливий клімат степової зони, негативний водний баланс, слабкорозвинуту гідрографічну мережу і недостатню площу водойм та прилеглих територій, на яких формується якість води. Дослідження водойм $\epsilon$ одними 3 найважливіших та пріоритетних в Україні та світі.

У посушливих умовах степової зони дослідження флори, рослинності озер та їх динаміки є важливими 3 декількох причин. По-перше, водні екосистеми є цінним середовищем існування великої кількості видів живих організмів, у тому числі рідкісних і зникаючих. По-друге, озера $є$ джерелами та резервуарами для збереження та накопичення прісної води. По-третє, водні рослини в своїй більшості є видами космополітними та розповсюджені у подібних екосистемах всього світу, тому такі дослідження дають можливість обміну даними про сучасний флористичний склад та динаміку розповсюдження гідрофітних видів рослин в озерах. До нашого часу дослідженню флори та рослинності озер даного регіону приділялося недостатньо уваги.

\section{Матеріали та методи досліджень}

Вища водна рослинність вивчалась 3 використанням загальноприйнятих геоботанічних (Ramenskij, 1971) i спеціальних гідроботанічних методик (Katanskaya, 1981), зокрема використовувався метод еколого-ценотичного профілювання. Для відбору занурених i плаваючих макрофітів використовувався «рачок-кішка» модифікації А. В. Свдущенко. Сучасні назви рослин надані за зведенням: Mosyakin, Fedorochuk Vascular plants of Ukraine (1999). Рослинні угруповання озерних екосистем описані за домінантною системою. Синтаксономія вищої водної рослинності наводилася за монографією І. Л. Корелякової «Растительность Кременчугского водохранилища» (1977). Матеріал був зібраний протягом 2009-2018 років самостійно та в складі загону біогідроценологів Комплексної експедиції Дніпропетровського університету (Baranovskyi, Voloshina, 2009, 2012; Voloshina, 2014; Roshchyna, 2016, 2017). Вивчення флори та рослинності озер здійснювалося під час маршрутних (воднотранспортних, автотранспортних, пішохідних), стаціонарних (Присамарський біосферний стаціонар) та напівстаціонарних досліджень (ПЗДО). Проаналізовано сучасне та колишнє розповсюдження вищої водної рослинності озер заплав, арен та третіх терас долин великих та середніх річок Північно-Степового Придніпров'я.

Природні озера Північно-Степового Придніпров'я розташовані в основному в долинах річок, тому територію умовно було поділено на ділянки: долину великої ріки (Дніпро) та долини середніх річок (Самара та Оріль). Сучасні дані отримані в результаті обробки матеріалів власних досліджень водної рослинності озер заплав, других піщаних терас та третіх солончакових терас. Для аналізу динаміки була проведена «реконструкція» існуючої раніше рослинності озер долин Дніпра, Самари та Орілі на основі літературних та архівних матеріалів (гербарію ДНУ та архіву НДІ біології) (Albickaya, 1948; Belgard, 1950; Baranovskyi, 2000, 2002, 2005, 2008, 2017; Tarasov, 2012; Schindler et al., 2016).

\section{Результати та їх обговорення}

Залежно від розподілу у водоймах та екологобіологічних особливостей макрофіти та їх угруповання поділяють на 3 екологічні групи: гідатофіти (занурені рослини, в яких увесь життєвий цикл проходить під водою, a генеративні пагони можуть підвищуватись над поверхнею води); плейстофіти (рослини 3 плаваючими асиміляційними органами, більша частина вегетативних пагонів і листків плаває на поверхні води); гелофіти (повітряно-водяні рослини 3 пагонами, частина яких знаходиться у воді, а частина - над поверхнею) (Katanskaya, 1981; Korelyakova, 1977; Dubyna et al., 1993).

Склад вищої водної рослинності озер залежить від багатьох екологічних факторів. Серед них можна виділити дві групи: глобальні та місцеві. До глобальних відносяться кліматичні зміни (температура, опади) та антропогенні (створення водосховищ, зміни ландшафту, атмосферне забруднення і т.д.). До місцевих належать мікрокліматичні та антропогенні фактори конкретного водного середовища (світло, температура, газовий та сольовий склад, вміст органічних речовин, $\mathrm{pH}$ та ін.).

Загальними рисами глобальних змін клімату $\epsilon$ підвищення середніх сезонних температур та збільшення аридності, зокрема в Свропі (Dai, 2013; Linder et al., 2014), що особливо небезпечно для екосистем таких посушливих регіонів, як степова зона України. Взагалі підвищення температур відбувається в усьому світі, і цій проблемі приділяє увагу велика кількість вчених, зокрема, створеної 
в 1988 р. Міжурядової групи експертів зі змін клімату. У IV доповіді, оприлюдненій у 2007 р., зазначено, що протягом столітнього періоду (1906-2005рр.) глобальна температура зросла на $0,74{ }^{\circ} \mathrm{C}$. Причому в Європі підвищення виявилося майже в півтора рази більшим. За прогнозами Міжурядової групи експертів, у XXI ст. підвищення температури повинно продовжитися.

Річна кількість опадів у регіоні має тенденцію до збільшення. За 50 років збільшення опадів за різними метеостанціями становить від 35 до 107 мм, у середньому по області - 74 мм. У зв'язку з частими відлигами впродовж зим спостерігається по декілька разів утворення і схід снігового покриву. Зменшення снігонакопичення не сприяє весняному промиванню водойм, яке раніше обмежувало заростання заплавних озер повітряно-водною рослинністю та їх заболочуванню.

Головний фактор загрози розвитку та функціонуванню більшості водних екосистем - антропогенний вплив, який iз XX ст. посилюється тенденцією до багаторічних змін клімату (Settele et al., 2014), які значною мірою теж $є$ наслідком людської діяльності.

До антропогенних факторів, що впливають негативно, можна віднести: інтенсифікацію сільського господарювання: розорювання прибережних територій, необгрунтовану меліорацію земель, надмірний випас, розбудову транспортної та інженерної інфраструктури, урбанізацію, рекреацію, хімічне забруднення.

Особливо велике значення мало утворення каскаду водосховищ та ставків. У результаті зарегулювання та накопичення талої води в штучних водоймах відбулося згладжування піку весняної повені, яке забезпечувало весняне промивання заплавних озер.

Підвищення температури весняного та осіннього сезону призводить до пролонгації вегетаційного періоду, а літнього - до більш активного випаровування і зниження рівня води. Усе це викликає інтенсивне заростання повітряно-водною рослинністю.

Підвищення температури зимнього сезону не сприяє снігонакопиченню. Зменшення снігонакопичення (часті відлиги впродовж зим), зарегулювання річкового стоку (утворення каскаду водосховищ та ставків) та накопичення талої води в штучних водоймах спричинило згладжування піку весняної повені. Таким чином, зник єдиний фактор, який забезпечував весняне промивання та обмежував заростання заплавних озер повітряно-водною рослинністю та їх заболочування.

Рослинність заплавних водойм була представлена найбільш різноманітними формами внаслідок впливу трьох позитивних факторів: короткочасного впливу паводку (підвищення та зменшення рівня води), обводнення та опріснення їх талими водами, а також збагачення під час паводку алохтонними поживними речовинами.

Кліматичні фактори в сукупності 3 антропогенними здійснюють синергічну дію. Вона призводить до змін, що проходять в цілому в напрямку заміни угруповань вищої водної рослинності угрупованнями повітряно-водних рослин (табл. 1).

\section{Таблиця 1}

Класифікація та багаторічні зміни рослинності озер Північно-Степового Придніпров’я

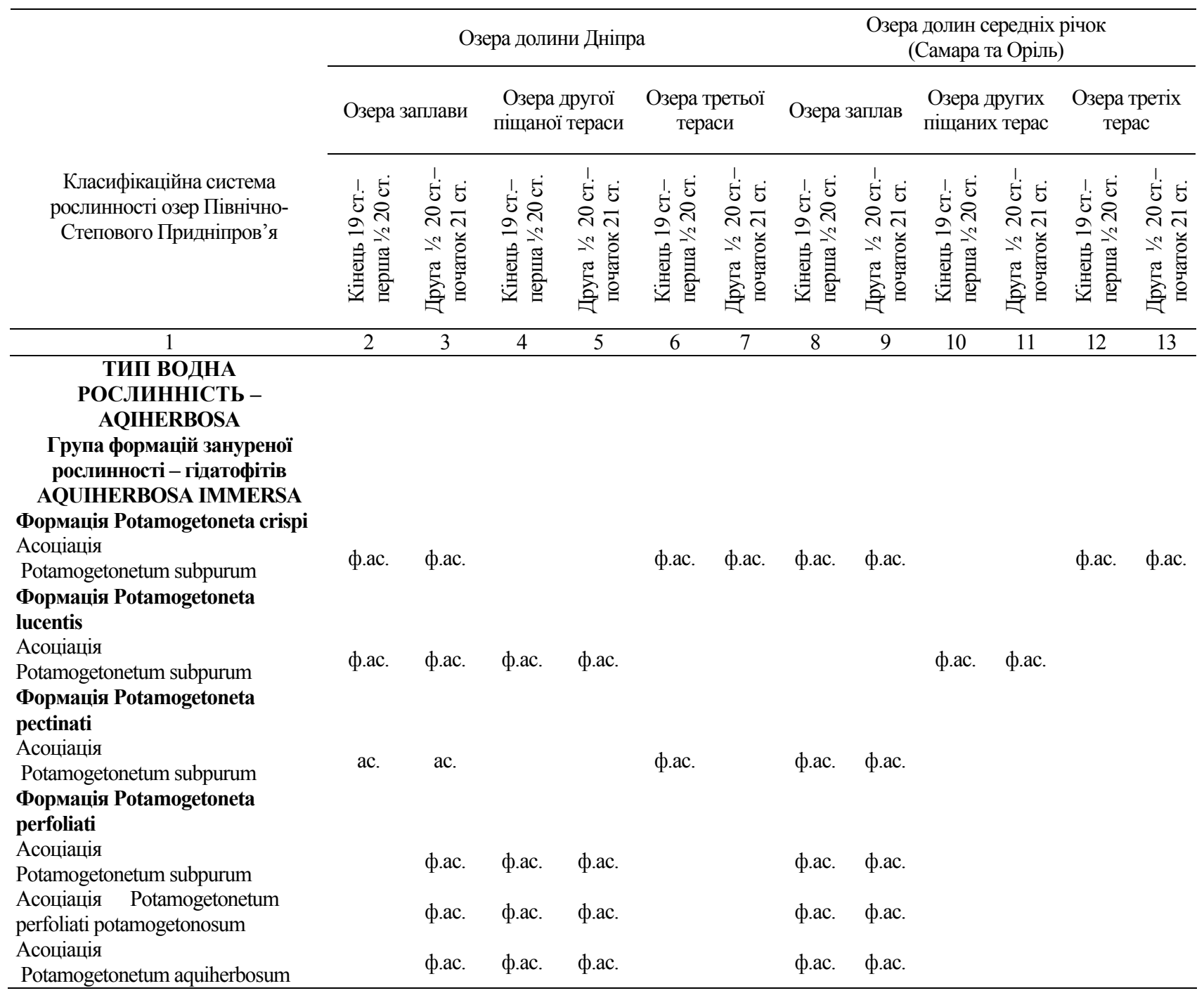


Продовження табл. 1

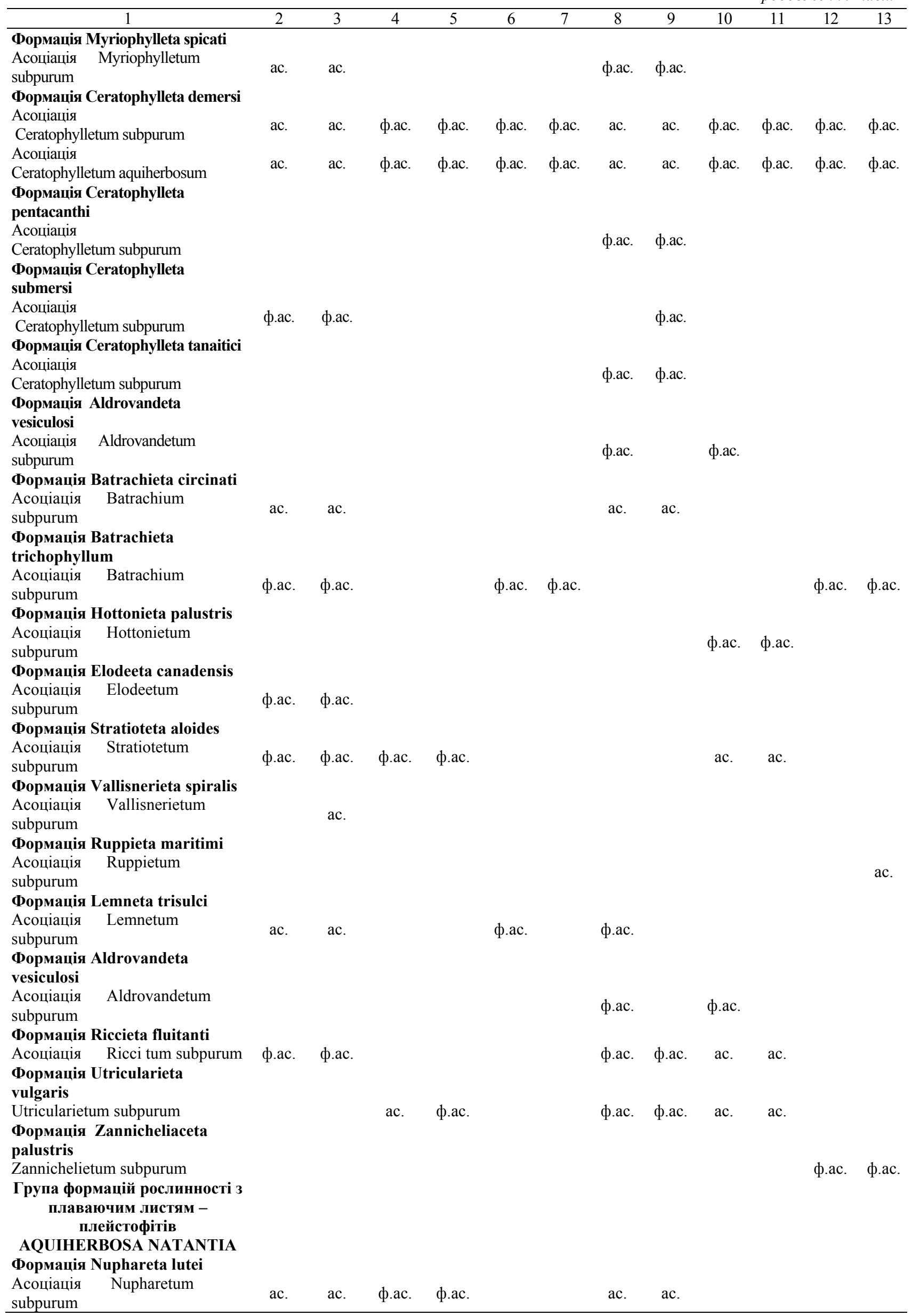


Продовження табл. 1

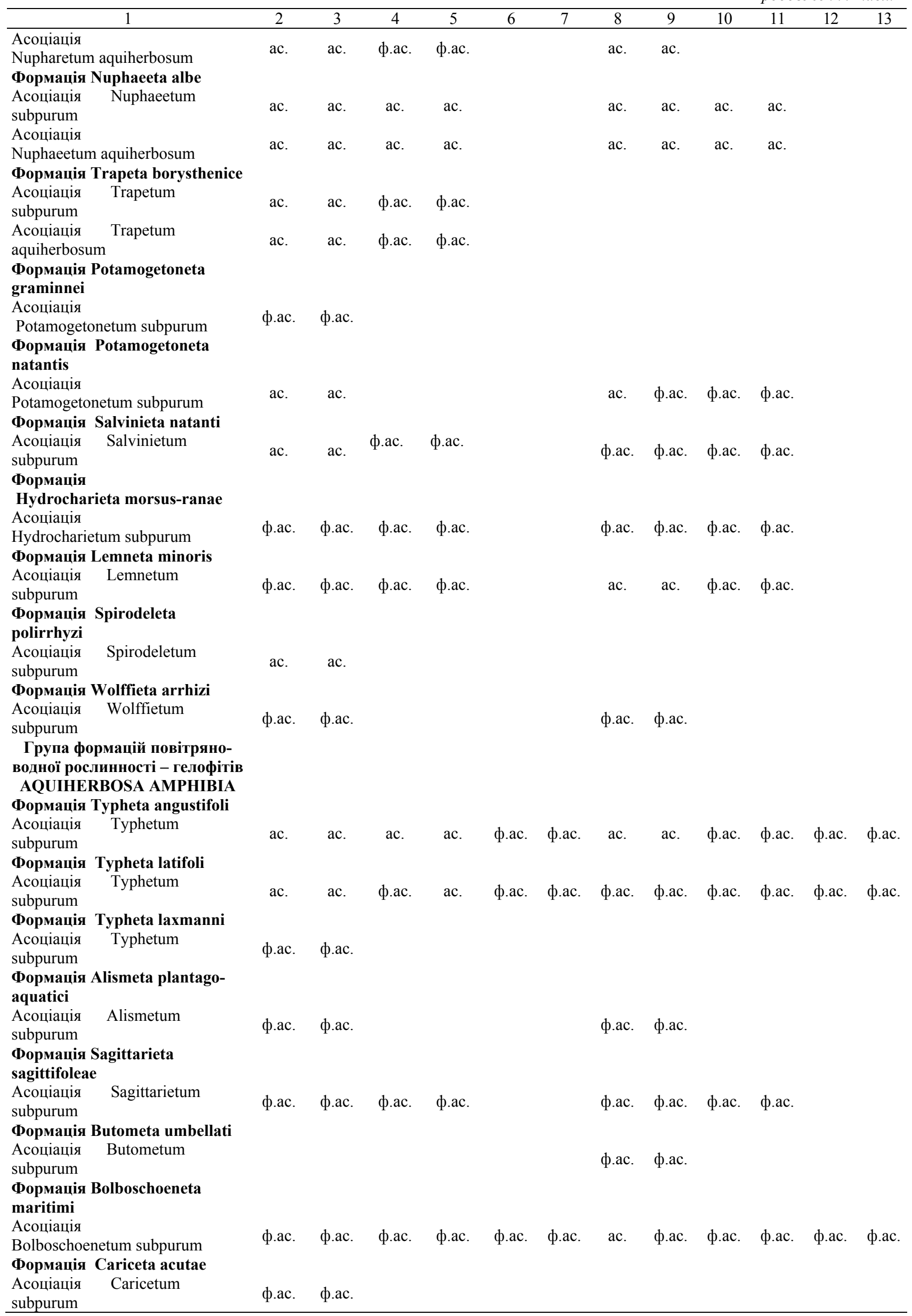




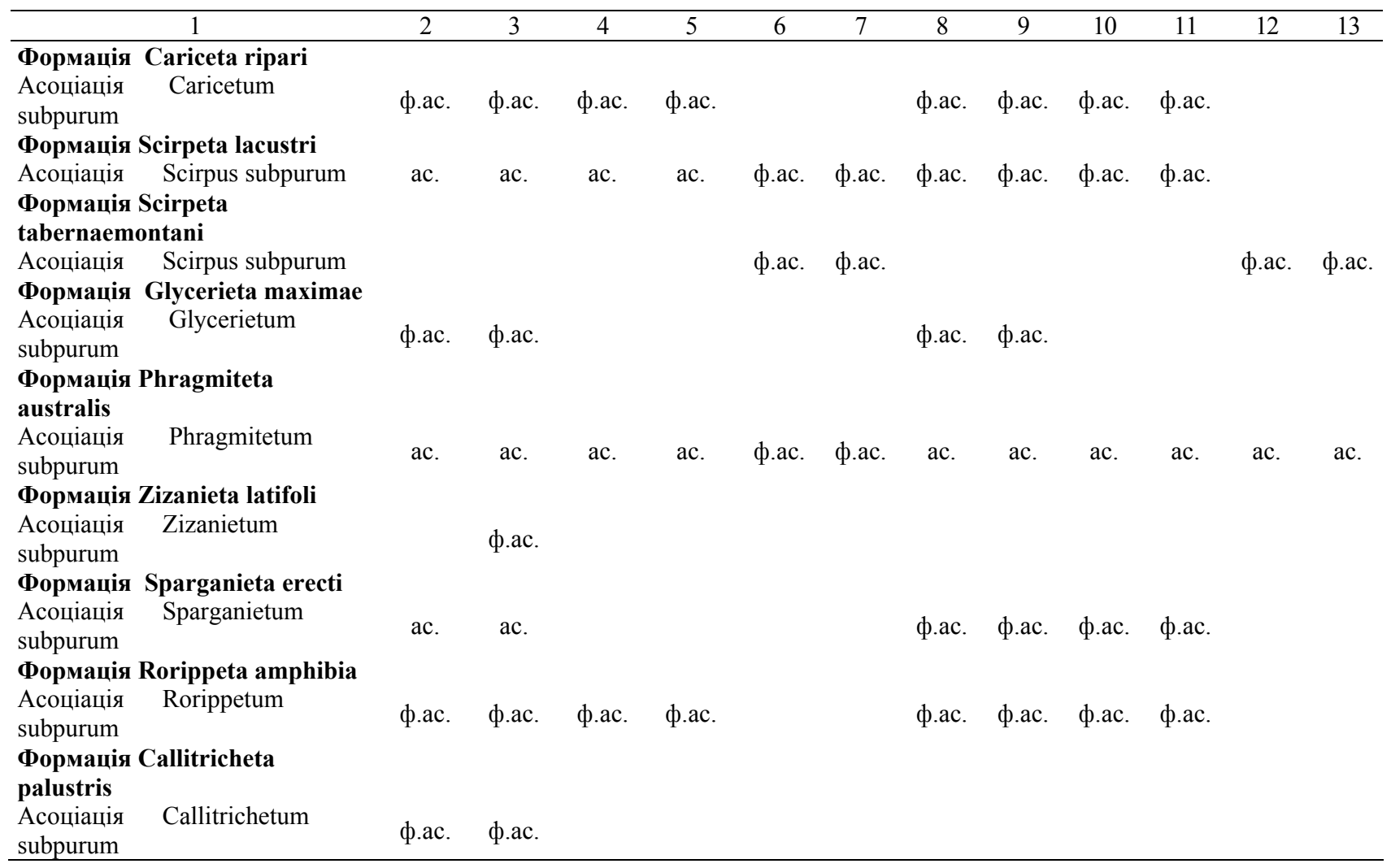

Умовні позначення: ас. - асоціація, ф.ас. - фрагмент асоціації.

Рослинність озер у межах заплави Дніпра практично не змінилася для всіх трьох груп формацій (табл. 2). Кількість угруповань занурених рослин озер у межах заплав середніх річок скоротилася на 3 асоціації. Асоціації плейстофітів та гелофітів зменшилися в кількості або залишилися фрагментарно.

Таблиця 2

Динаміка кількості асоціацій та фрагментів асоціацій
Рослинність озер у межах арени Дніпра практично не змінилася для всіх трьох груп формацій. Кількість асоціацій занурених рослин озер у межах арен середніх річок скоротилася на 2, а угруповання плейстофітів та гелофітів перейшли до рівня їх фрагментів.

\begin{tabular}{|c|c|c|c|c|c|c|c|c|c|c|c|c|}
\hline \multirow[b]{3}{*}{$\begin{array}{c}\text { Асоціації та } \\
\text { фрагменти } \\
\text { асоціацій }\end{array}$} & \multicolumn{6}{|c|}{ Озера долини Дніпра } & \multicolumn{6}{|c|}{ Озера долин середніх річок (Самара та Оріль) } \\
\hline & \multicolumn{2}{|c|}{ Озера заплави } & \multicolumn{2}{|c|}{$\begin{array}{c}\text { Озера другої } \\
\text { піщаної тераси }\end{array}$} & \multicolumn{2}{|c|}{$\begin{array}{c}\text { Озера третьої } \\
\text { тераси }\end{array}$} & \multicolumn{2}{|c|}{ Озера заплав } & \multicolumn{2}{|c|}{$\begin{array}{c}\text { Озера других } \\
\text { піщаних терас }\end{array}$} & \multicolumn{2}{|c|}{$\begin{array}{c}\text { Озера третіх } \\
\text { терас }\end{array}$} \\
\hline & 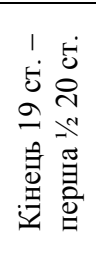 & 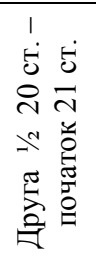 & 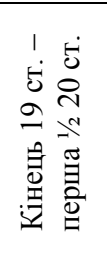 & 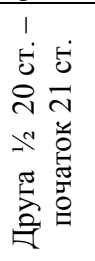 & 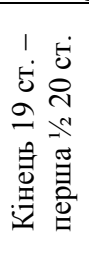 & 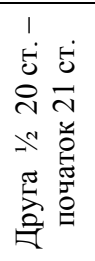 & 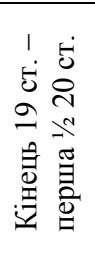 & 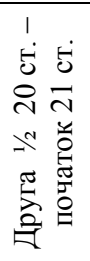 & 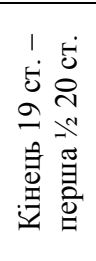 & 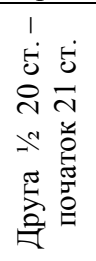 & 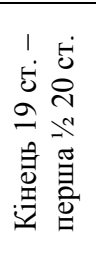 & 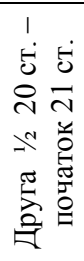 \\
\hline $\begin{array}{c}\text { Асоціації } \\
\text { гідатофітів } \\
\text { Фрагменти } \\
\text { асоціацій }\end{array}$ & 6 & 7 & 1 & - & - & - & 3 & 3 & 3 & 3 & - & 1 \\
\hline $\begin{array}{c}\text { гідатофітів } \\
\text { Асоціації }\end{array}$ & 10 & 10 & 7 & 8 & 6 & 4 & 13 & 11 & 6 & 4 & 5 & 5 \\
\hline $\begin{array}{c}\text { плейстофітів } \\
\text { Фрагменти } \\
\text { асоціацій }\end{array}$ & 9 & 9 & 2 & 2 & - & - & 6 & 5 & 2 & - & - & - \\
\hline $\begin{array}{c}\text { плейстофітів } \\
\text { Асоціашії }\end{array}$ & 4 & 4 & 7 & 7 & - & - & 3 & 4 & 4 & - & - & - \\
\hline $\begin{array}{c}\text { гелофітів } \\
\text { Фрагменти } \\
\text { асоціацій } \\
\text { гелофітів }\end{array}$ & 5 & 5 & 3 & 4 & - & - & 3 & 2 & 1 & 1 & 1 & 1 \\
\hline
\end{tabular}

У складі рослинності озер третьої тераси Дніпра фрагменти асоціацій двох видів вважаються зниклими. Кількість асоціацій занурених рослин озер третіх терас середніх річок збільшилася на одну за рахунок ценозів адвентивного південного виду Ruppia maritima. 


\section{Висновки}

Головний фактор загрози розвитку та функціонуванню більшості водних екосистем - антропогенний вплив, який iз XX століття посилюється тенденціями до багаторічних змін клімату, які значною мірою теж $є$ наслідком людської діяльності.

Підвищення температури зимнього сезону не сприяє снігонакопиченню. Зменшення снігонакопичення (часті відлиги впродовж зим), зарегулювання річкового стоку (утворення каскаду водосховищ та ставків) та накопичення талої води у штучних водоймах спричинило згладжування піку весняної повені як фактору, який забезпечував весняне промивання та обмежував заростання заплавних озер повітряно-водною рослинністю та їх заболочування.

Рослинність озер у межах заплави Дніпра практично не змінилася для всіх трьох груп формацій. Кількість угруповань занурених рослин озер у межах заплав середніх річок скоротилася на 3 . Асоціації плейстофітів та гелофітів перейшли 3 рівня асоціацій до рівня їх фрагментів. Рослинність озер в межах арени Дніпра практично не змінилася для всіх трьох груп формацій. Асоціації занурених рослин озер в межах арен середніх річок скоротилася на 2. У складі рослинності озер третьої тераси Дніпра фрагменти асоціацій двох видів вважаються зниклими. В межах третіх терас середніх річок з'явилася нова асоціація адвентивного південного виду Ruppia maritima L.

Зміни вищої водної рослинності характерні для озер усіх типів. Кліматичні фактори в сукупності 3 антропогенними здійснюють синергічну дію, яка призводить до незворотних змін у заростанні озер. Основними результатами такої трансформації водних екосистем на основі змін їх абіотичної та біотичної складової $є$ поступове підвищення мінералізації, замулення $\mathrm{i}$, як наслідок, інтенсивне заростання озер аборигенними та адвентивними видами 3 широкою екологічною амплітудою (заміщення ними видів, чутливих до змін середовища).

\section{References}

Albickaya, M. A. (1948). Opyt floristicheskogo analiza prisamarskih aren [Experience floristic analysis of prisamarias arenas]. Dnepropetrovsk. Nauchnye zapiski. Sbornik rabot biologicheskogo fakulteta, 27-40 (in Russian).

Baranovskyi, B. A. (2000). Rastitel'nost' ruslovogo ravninnogo vodohranilishha [Vegetation of the channel of the plain reservoir]. Dnepropetrovsk (in Russian).

Baranovskyi, B. A. (2002). Flora vodoemov basseyna r. Samary [Flora reservoirs of Samara River Basin]. Pytannya stepovoho lisoznavstva ta lisovoyi rekultyivatsiyi zemel, 31, 90-103 (in Russian).

Baranovskyi, B. A. (2005). Rastytelnost poymennykh vodoemov Prysamarya dneprovskoho [The vegetation of floodplain reservoirs Prisamarya Dnieper]. Pytannya stepovoho lisoznavstva ta lisovoyi rekul'tyvatsiyi zemel, 34, 90-94 (in Russian).

Baranovskyi, B. O. (2008). Analiz florystychnoho riznomanittya richkovykh dolyn Prysamarya na suchasnomu etapi doslidzhen [Analysis of floristic diversity river valleys Prysamarya at the current stage of research]. Pytannya stepovoho lisoznavstva, 37, 91-94 (in Ukrainian).

Baranovskyi, B. O., Manjuk, V. V., Ivan'ko, I. A., Karmyzova, L. O. (2017). Analiz flori nacional'nogo prirodnogo parku
«Oril's'kij» [Analysis of the Flora of the National Natural Park «Orelskiy»]. LIRA, Dnipro (in Ukrainian).

Baranovskyi, B. O., Voloshina, N. O., Karmyzova, L. A. (2009). Mnogoletnyaya dinamika gigrofilnoj flory pojmy Dnepra v predelah Dnepropetrovskoj oblasti [Perennial dynamics of hygrophilic flora of the Dnieper floodplain within the Dnipropetrovsk region]. Kremenchuk (in Russian).

Baranovskyi, B. O., Voloshina, N. O. (2012). Analiz adventivnoyi flori vodojm Dnipropetrovshini [An analysis of the Dnipropetrovsk reservoirs adventitious flora]. Pereyaslav-Hmelnickij (in Ukrainian).

Belgard, A. L. (1950). Lesnaya rastitelnost yugo-vostoka USSR [Forest vegetation of southeast Ukrainian SSR]. KSU, Kiev (in Russian).

Dai, A. (2013). Increasing drought under global warming in observations and models. Nature Climate Change, 3, 52-58.

Dubyna, D. V., Gejny, S., Groudova, Z. (1993). Makrofity indikatory izmenenij prirodnoj sredy [Macrophytes are indicators of changes in the natural environment]. Kiev (in Russian).

Katanskaya, V. M. (1981). Vysshaya vodnaya rastitelnost kontinentalnyh vodoemov SSSR [Higher aquatic vegetation of continental waters of the USSR]. Leningrad (in Russian).

Korelyakova, I. L. (1977). Rastitelnost Kremenchugskogo vodohranilisha [Vegetation of the Kremenchug reservoir]. Kiev (in Russian).

Linder, M., Fitzgerald, J. B., Zimmermann, N. E., Reyer, C., Delzon, S. (2014). Climate change and European forests: What do we know, what are the uncertainties, and what are the implications for forest management? Journal of Environmental Management, 146, 69-83.

Mosyakin, S. L., Fedoronchuk, M. M. (1999). Vascular plants of Ukraine (Nomenclatural checklist). Naukova dumka, Kyiv, 346 p.

Ramenskij, L. G. (1971). Problemy i metody izucheniya rastitelnogo pokrova. Izbrannye raboty [Problems and methods of studying vegetation. Selected works]. Leningrad (in Russian).

Roshchyna, N. O. (2016). Florocenotichne riznomanittya ozer Prisamar'ya u porivnyanni zi shtuchnimi vodojmami [Florocenotic diversity of the Prysamaria lakes in comparison with artificial reservoirs]. Pitannya stepovogo lisoznavstva ta lisovoyi rekultivaciyi zemel. DNU, Dnipro (in Ukrainian).

Roshchyna, N. O. (2017). Floristichne riznomanittya ozer Nacionalnogo prirodnogo parku «Orilskij» [Floral diversity of the Orilsky National Nature Park lakes]. Kyiv (in Ukrainian).

Schindler, S., O’Neill, F. H., Biró, V., Damm, C., Gasso, V., Kanka, R. (2016). Multifunctional floodplain management and biodiversity effects: a knowledge synthesis for six European countries. Biodiversity and Conservation, 25, 1349-1382.

Settele, J., Scholes, R., Betts, R. (2014). Terrestrial and inland water systems. Climate change 2014: impacts, adaptation, and vulnerability. Part A: global and sectoral aspects. Cambridge: Cambridge University Press, 271-359.

Tarasov, V. V. (2012). Flora Dnipropetrovskoy ta Zaporizkoy oblastey [Dnipropetrovsk and Zaporizhia regions flora]. DNU, Lira, Dnipropetrovsk (in Ukrainian).

Voloshina, N. O. (2014). Porivnyalnij analiz flori ozer dolini Samari v rajoni Prisamarskogo biosfernogo stacionaru [Comparative analysis of the Samaras valley lakes flora near the Prysamarsky Biosphere Reserve]. Kharkiv (in Ukrainian). 